\title{
Assessment of Rheumatic Mitral Stenosis severity by Mitral Leaflet Separation Index
}

\author{
Rajan Paudel', Ram Kishor Sah', Man Bahadur KC르, Deewakar Sharma², Arun Maskey², Rabi Malla ${ }^{2}$, \\ Sujeeb Rajbhandari², Prabha KC1, Rikesh Tamrakar², Binayak Gautam¹, Kunjang Sherpa'.
}

'Department of Cardiology, National Academy Of Medical Sciences, Bir Hospital, Kathmandu, Nepal

${ }^{2}$ Department of Cardiology, Sahid Gangalal National Heart Center, Kathmandu, Nepal

Corresponding Author: Rajan Paudel,

Department of Cardiology, National Academy of Medical Sciences,

Bir Hospital, Kathmandu, Nepal

Email: rajanpaude12066@gmail.com

ORCID ID NO: 0000-0002-6622-8628

Cite this article as: Paudel R., Sah R. K., KC. M. B., et al. Assessment of Rheumatic Mitral Stenosis severity by Mitral Leaflet Separation Index. Nepalese Heart Journal 2019; Vol 16 (2), 41-46

Submission date: $29^{\text {th }}$ June 2019

Accepted date: $3^{\text {rd }}$ September 2019

\section{Abstract}

Background and Aims: Determining the severity of mitral stenosis (MS) is important for both prognostic and therapeutic reasons. Measurement of Mitral valve area (MVA) by planimetry is gold standard and accurate but is highly operator dependent. Pressure Half Time (PHT) is affected by hemodynamic significance. In this Study we evaluated severity of mitral stenosis by mitral leaflet separation index (MLS index, MLSI). This new index could be useful surrogate measure of the MVA.

Methods: This is a hospital based, cross-sectional observational study carried out in Shahid Gangalal National Heart Centre (SGNHC), Kathmandu, Nepal. Study included 82 patients with Rheumatic MS who had undergone echocardiographic examination from July 2018 to December 2018. The maximal separation of the mitral valve leaflet tips was measured from inner edge to inner edge in end diastole in the parasternal long axis and apical 4-chamber views. These two parameters were averaged to yield the MLSI. The index was compared with mitral valve area determined by planimetry method and PHT.

Results: Of the 82 study subjects, majority were females $72(85.4 \%)$. The mean age of study patients was $37.33 \pm 11.56$ years. $30.5 \%$ had mild MS by planimetry, $31.7 \%$ had moderate MS and $37.8 \%$ had severe MS. There was a very strong correlation between MLS index and MVA by planimetry $(\mathrm{r}=0.89, \mathrm{p}<0.001)$ and MVA by PHT $(\mathrm{r}=0.95, \mathrm{p}<0.001)$. MLS index less than $0.73 \mathrm{~cm}$ can predict severe MS with $93.2 \%$ sensitivity and $89.3 \%$ specificity. On the other hand MLS index more than $1.035 \mathrm{~cm}$ can predict mild MS with $70 \%$ sensitivity and $89.3 \%$ specificity. Strong correlation exists between MLS index and MV severity in presence atrial fibrillation $(\mathrm{AF})(\mathrm{r}=0.879)$ for planimetry and $(\mathrm{r}=0.835)$ for PHT and in presence of coexisting mitral regurgitation (MR) $(\mathrm{r}=0.89)$ for planimetry and $(\mathrm{r}=0.86)$ for PHT.

Conclusion: MLSI has a strong correlation with MVA by planimetry and PHT. So, it can be used as a reliable method to assess severity of mitral stenosis and is a simple and easily obtainable. It has good correlation even in presence of AF and MR.

Keywords: Mitral stenosis, Mitral leaflet separation index, Planimetry, Pressure half time.

DOI: https://doi.org/10.3126/njh.v16i2.26316

\section{Introduction}

Rheumatic heart disease (RHD) has been one of the major forms of heart disease in developing countries like Nepal. It is also a major public health problem in Nepal as it affects young children and adolescents. Nepal has some of the highest frequency rates of rheumatic fever (RF) and RHD in the world. Rheumatic heart disease affects 1 in 100 school children in Eastern Nepal which includes subclinical RHD also, and is primarily clinically silent and may be more common among girls ${ }^{1}$.

The prevalence of rheumatic heart disease among school children of Kathmandu was found to be 1.2/1000 with mitral regurgitation being the commonest lesion ${ }^{2}$. Another study found the prevalence Rheumatic heart disease to be 0.90 per thousand in the age group $5-16$ years $^{3}$.

@ Nepalese Heart Journal. Nepalese Heart Journal retain copyright and works is simultaneously licensed under Creative Commons Attribution License CC - By 4.0 that allows others to share the work with an acknowledge of the work's authorship and initial publication in this journal

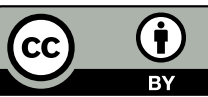


Rheumatic mitral stenosis is an acquired progressive valvular heart disease characterized by diffuse thickening of the mitral leaflets, fusion of the commissures, and shortening and fusion of the chordae tendineae, which occur as a sequelae to acute rheumatic fever. Determining the severity of mitral stenosis (MS) is important for both prognostic and therapeutic reasons. Transthoracic two-dimensional (2D) Doppler echocardiography is presently the gold standard method for assessment of severity of $\mathrm{MS}^{4}$. Transthoracic echo is non-invasive, widely available and easy to perform. The mitral valve area (MVA) can be measured by planimetry, pressure halftime (PHT), continuity equation, and proximal isovelocity surface area methods ${ }^{5,6}$.

Planimetry of the mitral valve orifice has the advantage of being a direct measurement of the MVA and, unlike other methods, flow conditions, cardiac chamber compliance, or associated valve lesions do not influence this parameter. In practice, planimetry has been shown to have best correlation with the anatomic valve area as assessed on explanted valves ${ }^{7}$. For these reasons, planimetry is considered as the reference measurement of $\mathrm{MVA}^{8}$. Haemodynamic changes might also have an impact on planimetric measurements. In cases of low stroke volume, planimetry might overestimate the severity of stenosis. Direct measurement of MVA by planimetry is accurate but is highly operator dependent and sometimes laborious 9 .

The reliability of the pressure half-time method is affected by changes in preload or left ventricular compliance. The transmitral gradient is also well correlated with MS severity. Transmitral gradient and continuity equation depend on transvalvular flow and may be affected by cardiac output and presence of mitral regurgitation ${ }^{9}$.

Mitral leaflet separation index as a measure of MS severity was first proposed by Fisher et al. in $1979^{10}$. The study showed a good correlation between maximum diastolic separation distance of the mitral leaflets measured by M-mode and MVA obtained invasively using the Gorlins' equation. Recently, the MLS index, measuring the distance between the tips of the mitral leaflets in parasternal longaxis and four-chamber views, was presented as a reliable measure of MS severity and as a surrogate for MVA ${ }^{11}$. The main advantage of the MLS index is its simplicity and ease of measurement in comparison with planimetry and PHT. It provides a quick estimate of MS severity from standard 2D echocardiographic views without having to resort to tedious measurements as it is technically easy to obtain.

In this Study, we evaluated severity Mitral stenosis by mitral leaflet separation index, henceforth referred as MLS index. This new index could be useful surrogate measure of the mitral valve area.

\section{Methods}

This is a Hospital based, cross-sectional observational study carried out in Shahid Gangalal National Heart Centre (SGNHC), Kathmandu, Nepal from July 2018 to December 2018.

After taking clearance from Institutional review board of National Academy of Medical Sciences (NAMS), 82 patients who fulfilled the inclusion criteria were included in the study.

\section{Inclusion criteria}

Patients of all age group who were diagnosed as a case of Rheumatic mitral stenosis and presenting in SGNHC for 2D Echocadiography from July 2018 to December 2018.

\section{Exclusion criteria}

1. Patients with suboptimal images and/or heavy mitral valvular calcification precluding the accurate measurement of cuspal separation.

2. Other significant valvular lesions.

3. Mitral stenosis other than rheumatic in Origin.
Study subjects

Consecutive patients of all ages and both sexes with rheumatic mitral stenosis who underwent echocardiography at Shahid Gangalal Heart Centre Kathmandu were enrolled for the study. Rheumatic MS was differentiated from non rheumatic MS by patients history and echocardiography suggestive of rheumatic involvement characterized by thickening and calcification that begins at the leaflet tips and extends into the subvalvular apparatus ${ }^{12}$. In the study population, the mitral valve area was estimated by the standard $2 \mathrm{D}$ echo planimetry and pressure half time methods. The MLS index was estimated by measuring the maximal separation of tip of the mitral leaflets in end diastole in parasternal long axis (PLAX) view and in apical 4-chamber view (A4C) (fig1). For patients in sinus rhythm, three measurements was obtained in PLAX and A4C view each. An average of this was taken as MLS index. For patients in atrial fibrillation, five measurements were taken in PLAX view and five measurements in A4C view. An average of this was considered as the MLS index. MLS index was compared with MVA assessed by planimetry and PHT. Severe MS was defined as MVA of $1 \mathrm{~cm}^{2}$ or less by planimetry or pressure half-time. Moderate MS was defined as MVA between $1 \mathrm{~cm}^{2}$ and $1.5 \mathrm{~cm}^{2}$ by planimetry or pressure half-time method. Mild MS was defined as an MVA of more than $1.5 \mathrm{~cm}^{2}$ by planimetry or pressure halftime $^{13}$. Other echocardiographic parameters taken were mitral mean and peak gradients, left atrial (LA) size, left ventricular (LV) size, ejection fraction (EF).

Questions about demographic features like age, sex, address, occupation, literacy level were also asked. Patients were classified as literate or illiterate according to national literacy policy of Nepal.

Figure1. Mitral Leaflet Separation Index (MLSI) Measurement, Parasternal Long Axis View and Apical 4-Chamber view.

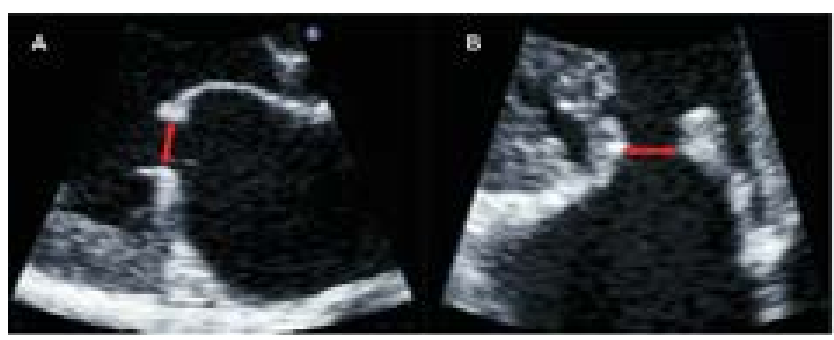

\section{Statistical analysis}

All data were entered into an electronic spread sheet (Microsoft Excel) and SPSS version 20 software for windows XP. All parametric values were expressed as mean \& nonparametric values were expressed in percentage (\%). Linear regression analysis was used to correlate MLS index against MVA by planimetry and PHT method. The value of MLS index which predicted mild and severe MS with best sensitivity and specificity was determined by receiver operating characteristic curve analysis.

\section{Results}

Among 82 rheumatic mitral stenosis patients, majority were females $72(85.4 \%)$ and $12(14.6 \%)$ were male (Fig 2). The mean age of study patients was $37.33 \pm 11.56$ years. Age of patients ranged from 14 years of age and to 66 years. Majority of patients belonged to age group $20-40$ years. $61 \%$ of patients were illiterate, $50 \%$ of patients were on penicillin prophylaxis, $97.6 \%$ had LA enlargement, 30.5\% were in atrial fibrillation and $4.9 \%$ of patients were taking oral 
anticoagulant. Out of 82 patients $30.5 \%$ had mild MS by planimetry, $31.7 \%$ had moderate MS and $37.8 \%$ had severe MS. Mean LA size was significantly larger in patients with AF compared to those without AF. Mean age of patients with AF was $42.32 \pm 12.57$ years and $35.14 \pm 10.48$ years in patients without AF. Although the age of patients were more in patients with AF but it was not statistically significant $(\mathrm{p}=0.20)($ Table 1$)$.

Table 1: : Baseline Characteristics of Patients:

\begin{tabular}{|c|c|c|c|}
\hline \multicolumn{2}{|l|}{ Parameters } & $\begin{array}{l}\text { Frequency } \\
(\mathrm{N}=\mathbf{8 2})\end{array}$ & $\begin{array}{l}\text { Percentage } \\
(\%)\end{array}$ \\
\hline \multicolumn{2}{|l|}{ Age (Mean \pm SD) } & \multicolumn{2}{|c|}{$37.33 \pm 11.56$} \\
\hline \multirow[t]{3}{*}{ Age group } & 20 years & 4 & 4.9 \\
\hline & $20-40$ years & 45 & 54.9 \\
\hline & $>40$ years & 33 & 40.2 \\
\hline \multirow[t]{2}{*}{ Sex } & Male & 12 & 14.6 \\
\hline & Female & 70 & 85.4 \\
\hline \multirow[t]{2}{*}{ literate } & Yes & 32 & 39 \\
\hline & No & 50 & 61 \\
\hline \multirow{2}{*}{$\begin{array}{l}\text { Penicillin } \\
\text { prophylaxis }\end{array}$} & Yes & 41 & 50 \\
\hline & No & 41 & 50 \\
\hline \multirow[t]{2}{*}{ LA Enlargement } & Yes & 80 & 97.6 \\
\hline & No & 2 & 2.4 \\
\hline \multirow{2}{*}{$\begin{array}{l}\text { Atrial } \\
\text { Fibrillation }\end{array}$} & Yes & 25 & 30.5 \\
\hline & No & 57 & 69.5 \\
\hline \multirow[t]{3}{*}{ Severity of MS } & Mild & 25 & 30.5 \\
\hline & Moderate & 26 & 31.7 \\
\hline & Severe & 31 & 37.8 \\
\hline $\begin{array}{l}\text { Mean Gradient } \\
(\text { Mean } \pm \text { SD) }\end{array}$ & \multicolumn{3}{|c|}{$10.56 \pm 5.12$} \\
\hline
\end{tabular}

Fig-2: Gender Distribution (\%)

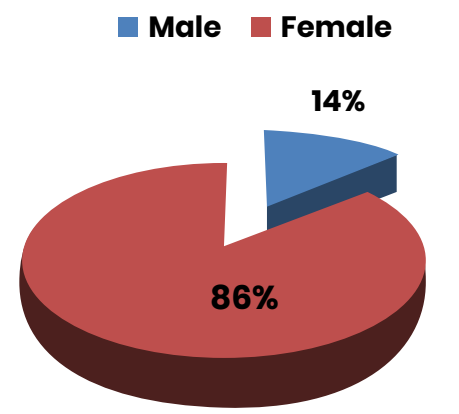

Fig-3 Age Distribution (yrs)

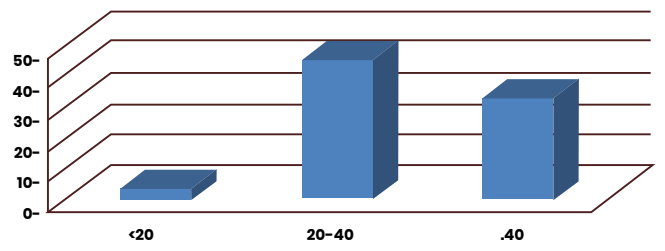

Fig-4 Severity of MS (\%)

\section{Mild MS Moderate MS Severe MS}

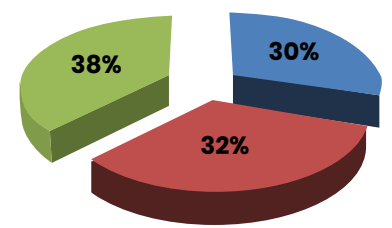

There was a very strong correlation between MLS index and mitral valve area (MVA) by planimetry using Pearson correlation $(r=0.89$, $\mathrm{p}<0.001)$. Also, there was a very strong correlation between MLS index and MVA by PHT $(r=0.95, \mathrm{p}<0.001)$.(Table 2, fig 5, 6)

Table 2: Correlations

\begin{tabular}{|c|c|c|c|c|}
\hline & & $\begin{array}{l}\text { MVA by } \\
\text { plannimetry }\end{array}$ & $\begin{array}{l}\text { MLS } \\
\text { index }\end{array}$ & $\begin{array}{l}\text { MVA by } \\
\text { PHT }\end{array}$ \\
\hline & $\begin{array}{l}\text { Pearson } \\
\text { Correlation }\end{array}$ & 1 & $.892 * *$ & $.954 * *$ \\
\hline \multirow[t]{3}{*}{$\begin{array}{l}\text { MVA by } \\
\text { plannimetry }\end{array}$} & $\begin{array}{l}\text { Sig. } \\
\text { (2-tailed) }\end{array}$ & & .000 & .000 \\
\hline & $\mathrm{N}$ & 82 & 82 & 82 \\
\hline & $\begin{array}{l}\text { Pearson } \\
\text { Correlation }\end{array}$ & $.892 * *$ & 1 & $.892 * *$ \\
\hline \multirow[t]{3}{*}{ MLS index } & $\begin{array}{l}\text { SIG. } \\
(2 \text {-TAILED) }\end{array}$ & .000 & & .000 \\
\hline & $\mathrm{N}$ & 82 & 82 & 82 \\
\hline & $\begin{array}{l}\text { Pearson } \\
\text { Correlation }\end{array}$ & $.954 * *$ & $.892 * *$ & 1 \\
\hline \multirow[t]{2}{*}{$\begin{array}{l}\text { MVA by } \\
\text { PHT }\end{array}$} & $\begin{array}{l}\text { Sig. } \\
\text { (2-tailed) }\end{array}$ & .000 & .000 & \\
\hline & $\mathrm{N}$ & 82 & 82 & 82 \\
\hline
\end{tabular}

**. Correlation is Significant at the 0.01 Level (2-tailed).

Figure-5: Linear Regression Graph Showing Correlation Between MLSI and MVA by Planimetry

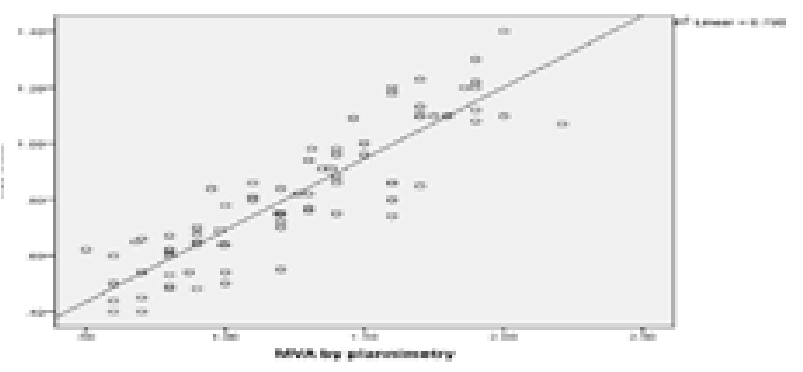


Figure-6: Linear Regression Graphic Showing Correlation Between MLSI and MVA by PHT

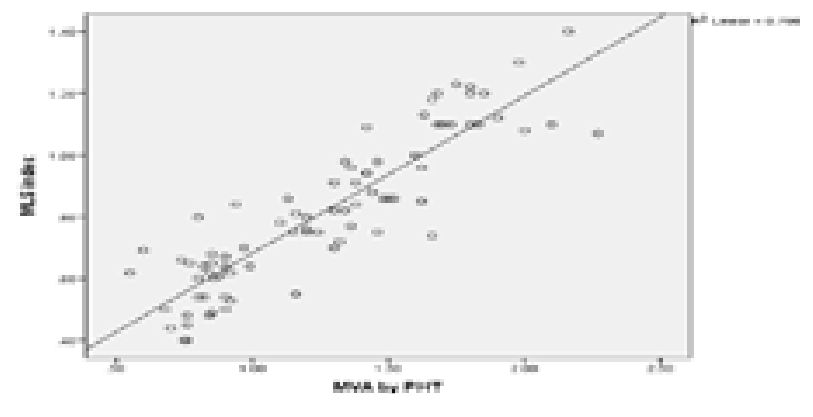

Using receiver operating characteristic (ROC) curve, MLS index less than $0.73 \mathrm{~cm}$ can predict severe MS with $93.2 \%$ sensitivity, $89.3 \%$ specificity. Area under the curve (AUC) for MLS in severe MS is 0.973 (Fig 7, 8).

Fig-7: Receiver Operating Characteristic Curve for Severe MS

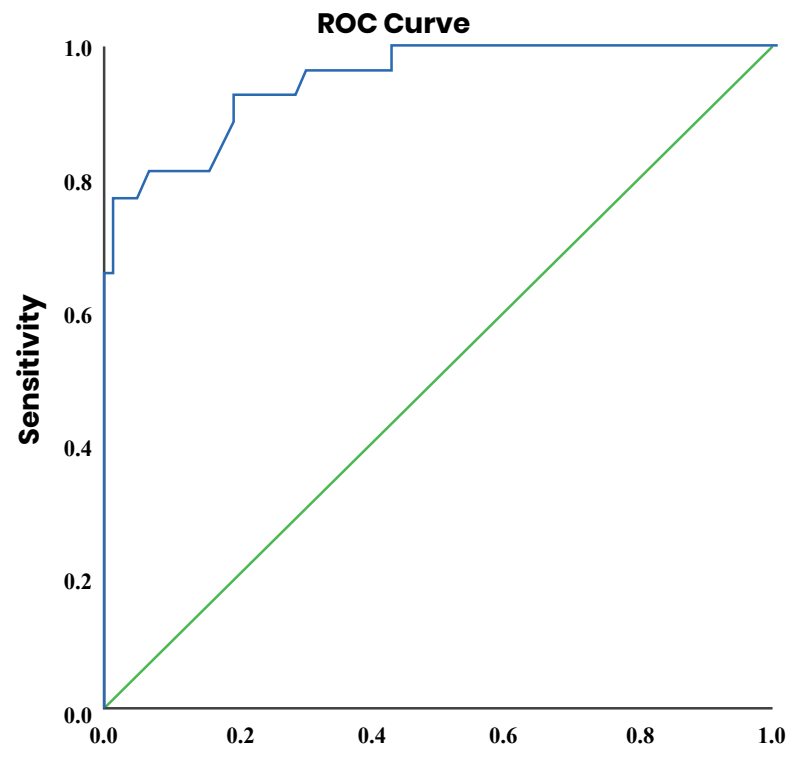

Using receiver operating characteristic (ROC) curve, MLS index more than $1.035 \mathrm{~cm}$ can predict mild MS with $70 \%$ sensitivity, $89.3 \%$ specificity and $0.90 \mathrm{~cm}$ can predict mild MS with $80 \%$ sensitivity and $85 \%$ specificity. Area under the curve for MLS in mild MS is 0.946 .

There was significant correlation between MLS index and MV severity in patients with MS and AF ( $\mathrm{r}=0.879)$ for planimetry and $(\mathrm{r}=0.835)$ for PHT. In presence of coexisting MR, correlation was also significant with correlation coefficient $(\mathrm{r}=0.89)$ for planimetry and $(\mathrm{r}=0.86)$ for PHT.

\section{Discussion}

The mitral leaflet separation (MLS) index, measures the distance between the tips of the mitral leaflets in parasternal long-axis and four- chamber views. These two readings are averaged to yield the mitral leaflet separation index. Mitral leaflet separation index as a measure of MS severity was first proposed by Fisher et al. in $1979^{10}$.
Fig -8: Receiver Operating Characteristic Curve for Mild MS

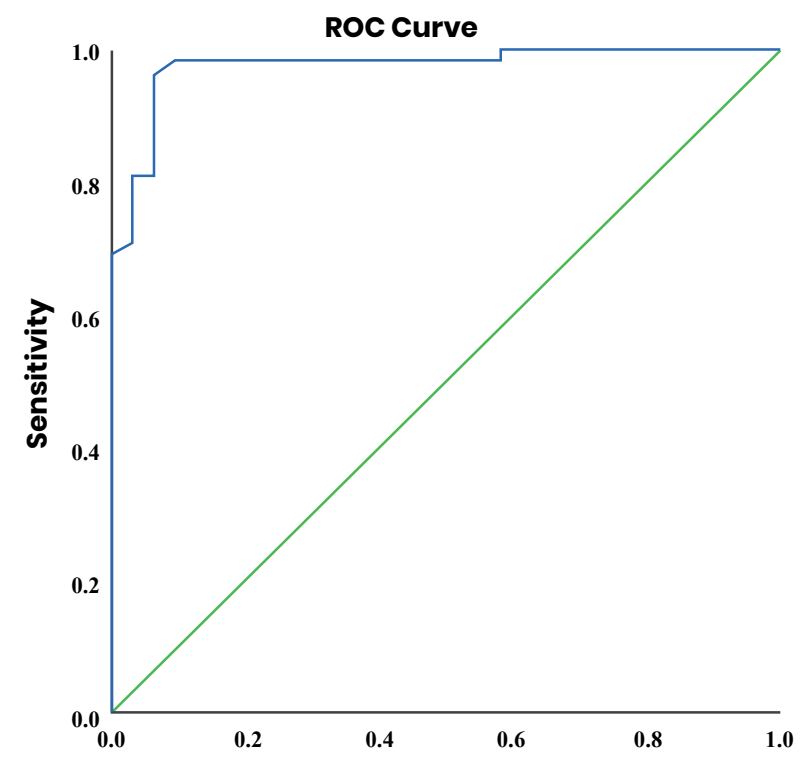

The study showed a good correlation between maximum diastolic separation distance of the mitral leaflets measured by M-mode and MVA obtained invasively using the Gorlins' equation.

In a study done by Seow SC et al. in 2006 the mitral leaflet separation index was measurable in $76(86.4 \%)$ patients. There was excellent correlation with mitral valve area by planimetry $(\mathrm{r}=0.91, \mathrm{P}<.001)$ and pressure half-time $(\mathrm{r}=0.86, \mathrm{P}<.001)$ across a wide range of mitral valve areas. Good correlation was found even in atrial fibrillation $(\mathrm{r}=$ 0.86 and $\mathrm{r}=0.79$, respectively). An index of $0.81 \mathrm{~cm}$ or less predicted severe MS with $92.3 \%$ sensitivity and $100 \%$ specificity whereas a value of $1.11 \mathrm{~cm}$ or more identified mild MS with $85.7 \%$ sensitivity and $100 \%$ specificity ${ }^{11}$.

A study done by Vimal Raj BS, George P, Jose VJ et al included one hundred and fifty consecutive patients with MS who underwent 2D echo. In each patient the severity of MS was assessed using 2D mitral valve area, pressure half time and MLS index. The MLS index correlated very well with MVA by planimetry $(r=0.87, \mathrm{P}<0.0001)$ and pressure half time $(\mathrm{r}=0.86, \mathrm{P}<0.0001)$. Good correlation was found even in atrial fibrillation $(\mathrm{r}=0.87$ and $\mathrm{r}=0.87$, respectively). ROC curve demonstrated that MLS index of $0.80 \mathrm{~cm}$ or less identified severe MS with $92 \%$ sensitivity and $92 \%$ specificity. MLS index of $>1.11 \mathrm{~cm}$ identified mild MS with $97 \%$ sensitivity and $97 \%$ specificity $^{14}$.

Study done by Joby K. Thomas, T. M. Anoop et al found that MLS index is a reliable measure of MS severity, which can be used as an easily obtainable adjunct and sometimes as a surrogate to current methods of assessment but not as a replacement for other echo parameters. This index would also help when there is a discrepancy between severities of MS estimated by existing methods, in the presence of atrial fibrillation and in the presence of mitral regurgitation'.

With the review of literatures, we evaluated a simple independent measure of severity mitral stenosis by MLS index hoping that this new index could be useful surrogate measure of the mitral valve area. Our findings are similar with the previous studies. MLS index demonstrates a very well correlation with MVA by planimetry and the PHT methods.

Findings of this study suggests that rheumatic mitral stenosis is common in females than males. Most of the patients were young with mean age 37 years most of them belonging to group $20-40$ years. Atrial 
fibrillation was present in $30.5 \%$ of patients. Mean age of patients with AF was $42.32 \pm 12.57$ and patients in sinus rhythm was $35.14 \pm 10.45$ $30.5 \%$ of patients had mild MS, $31.7 \%$ had moderate MS and $37.8 \%$ had severe MS. These findings were similar to previous studies. In a study done by Vimal Raj BS, George P, Jose VJ et al included one hundred and fifty consecutive patients, there were $34(22.7 \%)$ patients with mild MS, $52(34.7 \%)$ patients with moderate MS and $64(42.7 \%)$ patients with severe MS. One hundred and ten (73.3\%) patients were in sinus rhythm and $40(26.7 \%)$ patients were in atrial fibrillation ${ }^{14}$ Another study done by Eman M. Abdel Fattah, Sherif Mohamed Nasr et al found that in 50 patients with MS who have undergone echocardiography, Group1 consisted of 25 patients in sinus rhythm with mean age was $28.6 \pm 5.6$ years. Four of the patients were male (16\%), and 21 were female (84\%). Group II consisted of 25 patients suffering from atrial fibrillation. The mean age was $37.4 \pm 9.8$ years. Twelve of the patients were male $(48 \%), 13$ were female $(52 \%)^{15}$.

In our study, LA enlargement was found in $80(97.6 \%)$ of patients irrespective of severity of MS as also shown by Seow et $\mathrm{al}^{11}$ and Jacob Jose et $\mathrm{al}^{16}$. Mean LA size was larger in patients with atrial fibrillation than in sinus rhythm which was similar to previous studies. Mean LA size was $5.61 \pm 1.02 \mathrm{~cm}$ in patients with Atrial fibrillation and $4.43 \pm 0.38 \mathrm{~cm}$ in patients with sinus rhythm $(\mathrm{p}=<0.001)$.

We got similar findings with the previous studies while correlating MLS index with the severity of MS. MLS index demonstrates a very well correlation with MVA by planimetry and the PHT methods. In our study we found significant correlation between MLS and planimetry with correlation coefficient $(\mathrm{r}=0.89)$ and MLS with PHT(r=0.95).

The MLS index showed very good correlation with MVA by planimetry in subgroup analysis of patients with $\mathrm{AF}(\mathrm{r}=0.87)$. Also MLS index showed good correlation with MVA by planimetry in subgroup analysis of patients with coexisting mitral regurgitation( $(r=0.89)$. So, MLS Index can be used as a reliable tool to assess the severity of mitral stenosis in the presence of mitral regurgitation when mean gradient may overestimate the severity of mitral stenosis. MLSI is not intended to substitute the other echocardiography methods, but as an additional method that will strengthen in the determination of severity of mitral stenosis.

\section{Limitations of the study}

Heavily calcified valves and suboptimal images may have precluded accurate measurement of MLSI in some patients. This method is also operator dependant to a certain extent. Biasness in measurement of MLS index could be another limitation as the study was not blinded.

\section{Conclusion}

Mitral leaflet separation index has a strong correlation with MVA by planimetry and PHT. So it can be used as a reliable method to assess severity of Mitral stenosis and is a simple and easily obtainable. It has good correlation even in presence of atrial fibrillation and mitral regurgitation. Further studies can be undertaken in a larger group to evaluate the specificity and sensitivity of MLS index.

\section{Sources of funding: None}

\section{Conflict of Interest: None}

\section{References}

1. Shrestha NR, Karki P, Mahato R, et al. Prevalence of Subclinical Rheumatic Heart Disease in Eastern Nepal. A School-Based Cross-sectional Study. JAMA Cardiol. 2016;1(1):89-96. https://doi:10.1001/jamacardio.2015.0292
2. Bahadur KC, Sharma D, Shrestha MP, et al. Prevalence of rheumatic and congenital heart disease in schoolchildren of Kathmandu valley in Nepal. Indian Heart J. 2003 NovDec;55(6):615-18.

https://doi.org/10.1016/j.jcdr.2012.11.003

3. Prajapati D, Sharma D, Regmi PR, et al. Epidemiological survey of Rheumatic fever, Rheumatic heart disease and Congenital heart disease among school children in Kathmandu valley of Nepal. Nepalese Heart Journal 2013;10(1):1-5. https:// DOI: 10.3126/njh.v10i1.9738

4. R. A. Nishimura, C. S. Rihal, A. J. Tajik, and D. R. Holmes. Accurate measurement of the transmitral gradient in patients with mitral stenosis: a simultaneous catheterization and Doppler echocardiographic study. Journal of the American College of Cardiology.1994;24(1):152-58. https://doi.org/10.1016/0735-1097(94)90556-8

5. R.D.Rifkin, K.Harper and D.Tighe. Comparison of proximal isovelocity surface area method with pressure half-time and planimetry in evaluation of mitral stenosis. Journal of the American College of Cardiology.1995;26(2):458-65. https://doi.org/10.1016/0735-1097(95)80023-A

6. T. Y. Lee, T.-L. Hsu, C.-J. Tseng et al. Clinical applicability for the assessment of the valvular mitral stenosis severity with Doppler echocardiography and the proximal isovelocity surface area (PISA)method. Echocardiography.2004;21(1):1-6. https://doi.org/10.1111/j.07422822.2004.03057

7. Faletra F, PezzanoA Jr, Fusco R, et al. Measurement of mitral valve area in mitral stenosis: four echocardiographic methods compared with direct measurement of anatomic orifices. J Am Coll Cardiol.1996;28:1190-07. https://doi.org/10.1016/S0735-1097(96)00326-9

8. Onow RO, Carabello BA, Chatterjee K, et al. ACC/ AHA 2006 guidelines for the management of patients with valvular heart disease. A report of the American College of Cardiology/American Heart Association Task Force on Practice Guidelines (Writing committee to revise the 1998 guidelines for the management of patients with valvular heart disease). J Am Coll Cardiol.2006;48:e1-148. DOI:10.1016/j. jacc.2006.05.021

9. Joby K. Thomas, T.M. Anoop, Gailin B Sebastian, et al Mitral Leaflet Separation Index in Assessing the Severity of Mitral Stenosis. International Scholarly Research Network ISRN Cardiology. 2011, Article ID 768097, 4 pages doi:10.5402/2011/768097.

10. M. L. Fisher, A. F. Parisi, and G. D. Plotnick. Assessment of severity of mitral stenosis by echocardiographic leaflet separation. Archives of Internal Medicine.1979;139(4):402-6. doi:10.1001/archinte.1979.03630410012009

11. S.C.Seow, L.P.Koh, and T.C.Yeo. Hemodynamic significance of mitral stenosis: Use of a simple, novel index by 2-dimensional echocardiography. Journal of the American Society of Echocardiography.2006;19(1):102-6. https://doi.org/10.1016/j.echo.2005.07.012 
12. Lindman BR, Quader N. Mitral valve disease. In: Quader N, Makan M, Perez JE, editors. The Washington Mannual of Echocardiography $2^{\text {nd }}$ ed. Missouri: Walters Kluwer; 2017:137-58.

13. Helmut Baumgartner, Judy Hung et al. Echocardiographic assessment of valve stenosis: EAE/ASE recommendations for clinical practice. European Journal of Echocardiography. 2009;10(1):1-25. doi:10.1016/j.echo.2008.11.029

14. Vimal Raj BS, George P, Jose VJ. Mitral leaflet separation index-a simple novel index to assess the severity of mitral stenosis. Indian Heart J. 2008;60(6):563-66.
15. M.Abdelfattah, Sherif Mohamed Nasr, Zeinab Attiya Ashor, et al. Mitral Leaflet Separation Index Is

An Accurate Measure For Mitral Stenosis. JACC: CardiovascularInterventions.2013;6(2).DOI: 10.1016/j. jcin.2013.01.073

16. Sen PK, Pandey SR, Parulkar GB, et al. Mitral stenosis in young. Dis Chest 1966;49(4):384-92.

https://doi.org/10.1378/chest.49.4.384

17. Rao V, Christakis GT, Weisel RD, et al. Risk factors for stroke following coronary bypass surgery. J Card Surg. 1995;10(4 Suppl):468-74.

https://doi.org/10.1111/j.1540-8191.1995.tb00679.x 